Santos, MFF, Pereira, VCR, Guimarães Jr, PR \& Lúcio Neto, MP. (2020). Analysis of antimicrobial consumption in a community pharmacy in 2018. Research, Society and Development, 9(7):1-15, e378974278.

\title{
Análise do consumo de antimicrobianos em uma farmácia comunitária no ano de 2018
} Analysis of antimicrobial consumption in a community pharmacy in 2018 Análisis del consumo antimicrobiano en una farmacia comunitaria en 2018

Recebido: 06/05/2020 | Revisado: 06/05/2020 | Aceito: 08/05/2020 | Publicado: 17/05/2020

\section{Maria Francisca Ferreira dos Santos}

ORCID: https://orcid.org/0000-0003-3117-0267

Centro Universitário Santo Agostinho, Brasil

E-mail: franalana@hotmail.com

Valéria Cristina Rodrigues Pereira

ORCID: https://orcid.org/0000-0001-7857-5670

Centro Universitário Santo Agostinho, Brasil

E-mail: waleriaid23@ hotmail.com

Paulo Renzo Guimarães Júnior

ORCID: https://orcid.org/0000-0003-0873-8328

Faculdade Aliança Maurício de Nassau, Brasil

E-mail: renzo-acupuntura@hotmail.com

Manoel Pinheiro Lúcio Neto

ORCID: https://orcid.org/0000-0002-6411-7326

Centro Universitário Santo Agostinho, Brasil

E-mail: manoelplucio@hotmail.com

\section{Resumo}

É necessária prescrição médica para dispensação de antibacterianos em farmácias comunitárias, utilizados para vários tipos de doenças causadas por agentes bacterianos. $\mathrm{O}$ objetivo desta pesquisa foi obter o perfil do consumo de antibacterianos vendidos por uma farmácia comunitária em Teresina-PI. Tratou-se de um estudo de coorte retrospectivo realizado em um banco de dados de um estabelecimento referente a vendas de antibacterianos, por meio de análise documental com análise de conteúdo. Analisou a dispensação de antibacterianos de uma farmácia comunitária da cidade de Teresina-PI, referente a 2018, por meio de dados das vendas relatados ao Sistema Nacional de Gerenciamento de Produtos 
Controlados (SNGPC), realizada no banco de dados do Sistema Comercial Integrado (SCI). Os resultados foram apontados em gráficos confeccionados no programa Origin Pro 2016. No período analisado a farmácia comunitária vendeu 247 antibacterianos, prescritos a homens (140) e mulheres (107). A faixa etária populacional que mais necessitou da prescrição medicamentosa foi de adultos entre 21 a 50 anos. A maioria deles vindos de hospitais privados (163) pessoas e de hospitais do SUS (84). A concentração de venda de antimicrobianos foi entre os meses de fevereiro a maio, coincide com período chuvoso em Teresina, e este fator climático está relacionado ao aparecimento de doenças respiratórias. Os antibacterianos mais prescritos foram a amoxicilina (38), azitromicina (28) e tobramicina (28). A partir dos resultados foi possível obter o perfil de consumo de antibacterianos da referida farmácia e destacam-se as fármacos ligados a doenças respiratórias em relação à outras classes de doenças.

Palavras-chave: Serviços comunitários de farmácia; Antibacterianos; Medicamentos sem prescrição.

\begin{abstract}
A medical prescription is required for dispensing antibacterials in community pharmacies, used for various types of diseases caused by bacterial agents. The objective of this research was to obtain the profile of the consumption of antibacterials sold by a community pharmacy in Teresina - PI. This was a retrospective cohort study carried out on a database of an establishment referring to the sale of antibacterials, through document analysis with content analysis. Analyzed the dispensing of antibacterials from a community pharmacy in the city of Teresina - PI, for 2018, using sales data reported to the National Controlled Products Management System (SNGPC), carried out in the Integrated Commercial System (SCI) database ). The results were shown in charts made in the Origin Pro 2016 program. In the period analyzed, the community pharmacy sold 247 antibacterials, prescribed to men (140) and women (107). The population age group that most needed the prescription was adults between 21 and 50 years old. Most of them came from private hospitals (163) and SUS hospitals (84). The concentration of sale of antimicrobials was between February and May, coincides with the rainy season in Teresina, and this climatic factor is related to the appearance of respiratory diseases. The most prescribed antibacterials were amoxicillin (38), azithromycin (28) and tobramycin (28). Based on the results, it was possible to obtain the antibacterial consumption profile of the aforementioned pharmacy and the drugs linked to respiratory diseases stand out in relation to other disease classes.
\end{abstract}


Keywords: Community pharmacy services; Antibacterial agents; Nonprescription drugs.

\section{Resumen}

Se requiere una receta médica para dispensar antibacterianos en farmacias comunitarias, que se usan para varios tipos de enfermedades causadas por agentes bacterianos. El objetivo de esta investigación fue obtener el perfil del consumo de antibacterianos vendidos por una farmacia comunitaria en Teresina - PI. Este fue un estudio de cohorte retrospectivo llevado a cabo en una base de datos de un establecimiento que se refiere a la venta de antibacterianos, mediante análisis de documentos con análisis de contenido. Analizó la dispensación de antibacterianos de una farmacia comunitaria en la ciudad de Teresina - PI, para 2018, a través de datos de ventas informados al Sistema Nacional de Gestión de Productos Controlados (SNGPC), realizado en la base de datos del Sistema Comercial Integrado (SCI) ) Los resultados se mostraron en gráficos elaborados en el programa Origin Pro 2016. En el período analizado, la farmacia comunitaria vendió 247 antibacterianos, recetados a hombres (140) y mujeres (107). El grupo de edad de la población que más necesitaba la receta era adultos entre 21 y 50 años. La mayoría de ellos provenían de hospitales privados (163) y hospitales del SUS (84). La concentración de venta de antimicrobianos fue entre febrero y mayo, coincide con la temporada de lluvias en Teresina, y este factor climático está relacionado con la aparición de enfermedades respiratorias. Los antibacterianos más recetados fueron amoxicilina (38), azitromicina (28) y tobramicina (28). Con base en los resultados, fue posible obtener el perfil de consumo antibacteriano de la farmacia mencionada y los medicamentos relacionados con las enfermedades respiratorias se destacan en relación con otras clases de enfermedades.

Palabras clave: Servicios comunitarios de farmacia; Antibacterianos; Medicamentos sin prescripción.

\section{Introdução}

A dispensação de medicamentos para a comunidade que é considerada como um ato farmacêutico, na promoção a atenção farmacêutica e fundamental para as políticas públicas de saúde é realizado pelas Farmácias e Drogarias (São Paulo, 2015). Farmácia é um estabelecimento no qual presta serviços farmacêuticos, de interesse público e/ou privado, estruturado ao Sistema único de Saúde, que assiste a população com orientação sanitária e de insumo farmacêutico, com manipulação e dispersão de produtos diversos (Conselho Federal 
de Farmácia, 2001).

Para termos noção a respeito da quantidade de farmácias não hospitalares no país, levantamento feito pelo Conselho Federal de Farmácia apontaram 75.716 farmácias registradas no país, até o final de 2013, e chega a 78.321, se somar as que se encontram na clandestinidade (Brandão, 2014). A prática de ingestão de fármacos sem a prescrição médica, o aconselhamento e o acompanhamento de um profissional de saúde gabaritado se configura como automedicação (Silva \& Lazarini, 2014). A ocorrência da administração de medicações sem orientação adequada pode adiar o diagnóstico de uma doença grave, levar a alergias, interações medicamentosas e intoxicações, reduzir a efetividade do resultado e apresentar efeitos adversos indesejáveis, ter gastos não programados com dano a saúde do paciente (Conselho Federal de Farmácia, 2016).

Em estudo com idosos assistidos por um centro de referencia, sobre automedicação, se identificou mais de $80 \%$ da amostra automedicava-se, $36,5 \%$ destes com fármacos que necessitam de prescrição, sendo analgésicos e antipiréticos, e relaxantes musculares os mais comuns (Oliveira, Barroso, Bicalho \& Reis, 2018). Um estudo mais geral e a nível nacional apontou que mulheres de 20 a 39 anos são as responsáveis pela maior quantidade de automedicação em todas as regiões do país, geralmente, ligados a problemas do sistema nervoso central, aparelho musculo esquelético, trato alimentar e metabólico, sistema respiratório (Arrais et al., 2016).

A população em geral tem usado antibióticos em associação a sintomatologia de febre, este fator gerado principalmente por automedicação de antimicrobianos sem prescrição médica (Diaz, 2015). Um estudo evidenciou esta linha de pensamento quando fez um levantamento do percentual de vendas de antibióticos em uma farmácia de Fortaleza - CE e evidenciou que a maioria dos clientes, que compram medicamentos para tratar infecção urinária, não apresenta receita (Menezes, Oliveira, Cunha, Pinheiro \& Bezerra, 2004). Apesar de já existirem normas para combate à compra sem receita, quase 90\% da amostra de uma pesquisa feita em farmácias comunitárias em Cruz das Almas - BA sabia ser ilegal a venda sem prescrição de antibiótico, 34,72\% se automedica por receitas antigas e 51,28\% adquirem o mesmo fármaco para o mesmo tipo de problema (Santos, 2017).

Em Teresina as infecções bacterianas mais frequentes atingem o trato respiratório, de acordo com dados coletados entre 2014 e 2015, detectados em um hospital público de ensino (Veloso \& Campelo, 2017). O antibiótico mais comum quando se trata de infecção do trato respiratório é a penicilina, uma classe de fármacos que compõe a amoxicilina e suas associações (Andrade, Vasconcelos, Campos \& Camurça, 2019). 
A maior parte dos fármacos antibióticos comprados na farmácia são para infecção do trato respiratório, geralmente faringite e rinite, sendo que a azitromicina e a amoxilina se enquadram como aqueles mais vendidos em drogarias de Montes Claros - MG (Alves et al., 2014). Por conta de tudo que foi exposto acima, este estudo tem como objetivo obter o perfil de consumo de antibióticos de uma farmácia comunitária situada em Teresina - PI.

\section{Metodologia}

Nesta pesquisa foi empregado o estudo de campo apresentado por Pereira, et al. (2018). Neste estudo se observou banco de dados de um estabelecimento referente a vendas de antibióticos. Assim caracterizado como uma análise documental aplicando análise de conteúdo de maneira quali-quantitativa.

Tratou-se de um estudo de coorte retrospectivo, no qual analisou a dispersão de antimicrobianos de uma farmácia comunitária da cidade de Teresina - PI. Foi realizada em uma drogaria comunitária, atribuída a um investidor local, que funciona no Bairro São Pedro. De acordo com os dados obtidos pelo Censo 2010, existia aquela época 8780 habitantes, em sua maioria, mulheres 4714, e a maior faixa de concentração populacional entre 14 a 65 anos.

Este estudo analisou dados das vendas de antibióticos relatados junto ao Sistema Nacional de Gerenciamento de Produtos Controlados (SNGPC), um programa que veio para suprir as necessidades apontadas na Portaria Ministério da Saúde N. ${ }^{\circ}$ 344, de 12 de maio de 1998 a qual aprova o Regulamento Técnico sobre as substâncias e medicamentos sujeitos a controle especial e a Resolução da Diretoria Colegiada RDC N. ${ }^{\circ} 20$ de 5 de maio de 2011 que dispõe sobre o controle de medicamentos à base de substâncias classificadas como antimicrobianos, de uso sob prescrição, isoladas ou em associação, o foco da nossa pesquisa, no período de janeiro de 2018 a dezembro do mesmo ano.

A pesquisa não necessitou de aprovação pelo Comitê de Ética, por conta da utilização de dados secundários, os quais impossibilita identificar os indivíduos envolvidos, também não foi envolvido material biológico, respeitando os dispositivos da portaria do Conselho Nacional de Saúde CNS n. ${ }^{\circ}$ 466/2012.

Os dados foram coletados por meio de tabelas do banco de dados do Sistema Comercial Integrado (SCI), um sistema de automação ao controle e venda de medicamentos utilizados em farmácias. Em seguida utilizou-se o Microsoft Office Excel 2010 para confecção dos gráficos. 


\section{Resultados e Discussão}

A pesquisa trouxe vários dados com relação à utilização de uma farmácia comunitária em Teresina - PI, com a pauta do uso de antibióticos dispensados durante o ano de 2018. Para caracterizar a amostra foi apontada a distribuição da venda de antibióticos com relação ao sexo, observando os dados presentes nas 247 receitas, as quais foram anexadas no referido programa, para validar a venda de antimicrobianos a comunidade. Quanto ao gênero, as prescrições foram mais prevalentes nas mulheres, como indicado no Gráfico 1.

Gráfico 1: Quantidade de atendimentos farmacêuticos quanto à venda de antibióticos em 2018, quanto ao gênero.

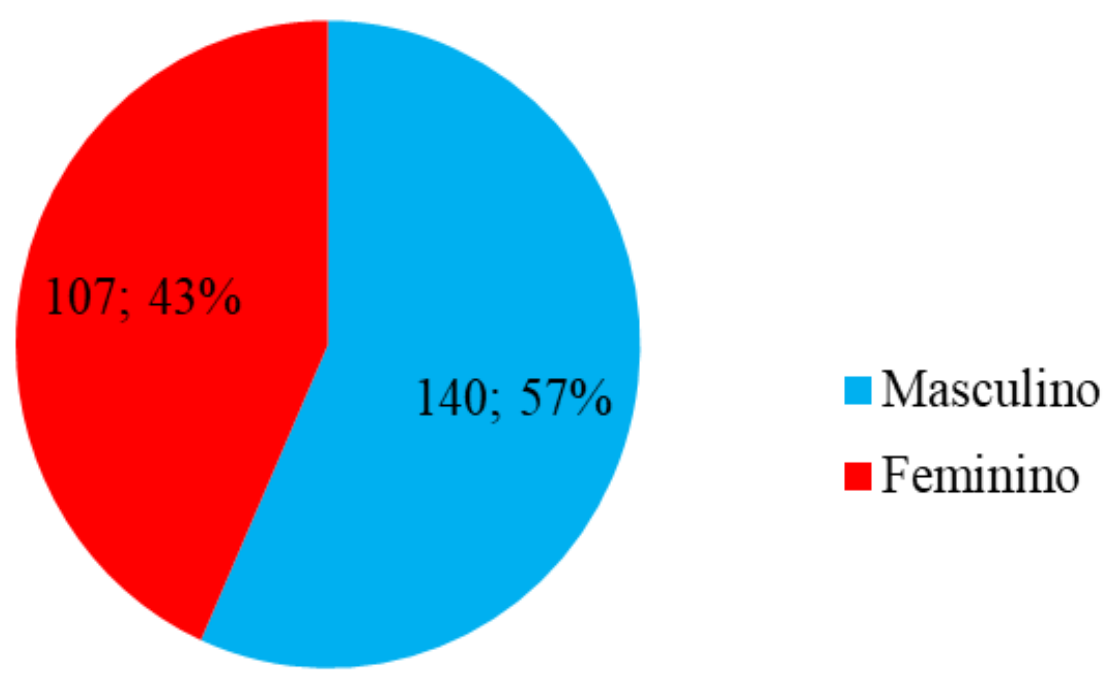

\section{Quanto ao Gênero}

* Fonte: dados da pesquisa (2019).

No Gráfico 1 é possível observar a quantidade e seu valor percentual em relação a venda de antibacterianos da farmácia comunitária com relação ao gênero. Pode-se inferir a tendência maior de prescrição para uso de antibióticos a indivíduos do sexo masculino.

Os resultados apontaram uma prevalência de 140 prescrições (57\%) para indivíduos do sexo masculino, ao passo que o sexo feminino representou 107 prescrições (43\%) das vendas para o consumo de antibacterianos de um total de 247 receitas prescritas. Esta evidencia aponta uma dispensa de antibióticos mais frequente para a população masculina 
(CC BY 4.0) | ISSN 2525-3409 | DOI: http://dx.doi.org/10.33448/rsd-v9i7.4278

assistida pela farmácia, todavia dados publicados apontam maior consumo pelo sexo feminino, o que contrastou com o resultado encontrado (Braoios, et al., 2013).

Outra característica que foi verificada para a caracterização da amostra tratou-se da idade dos pacientes os quais necessitaram de antibióticos, categorizando-os por década etária, como pode ser visualizada no Gráfico 2.

Gráfico 2: Quantidade de vendas de antibióticos em 2018 retidas do SCI da farmácia comunitária pesquisada, por década etária.

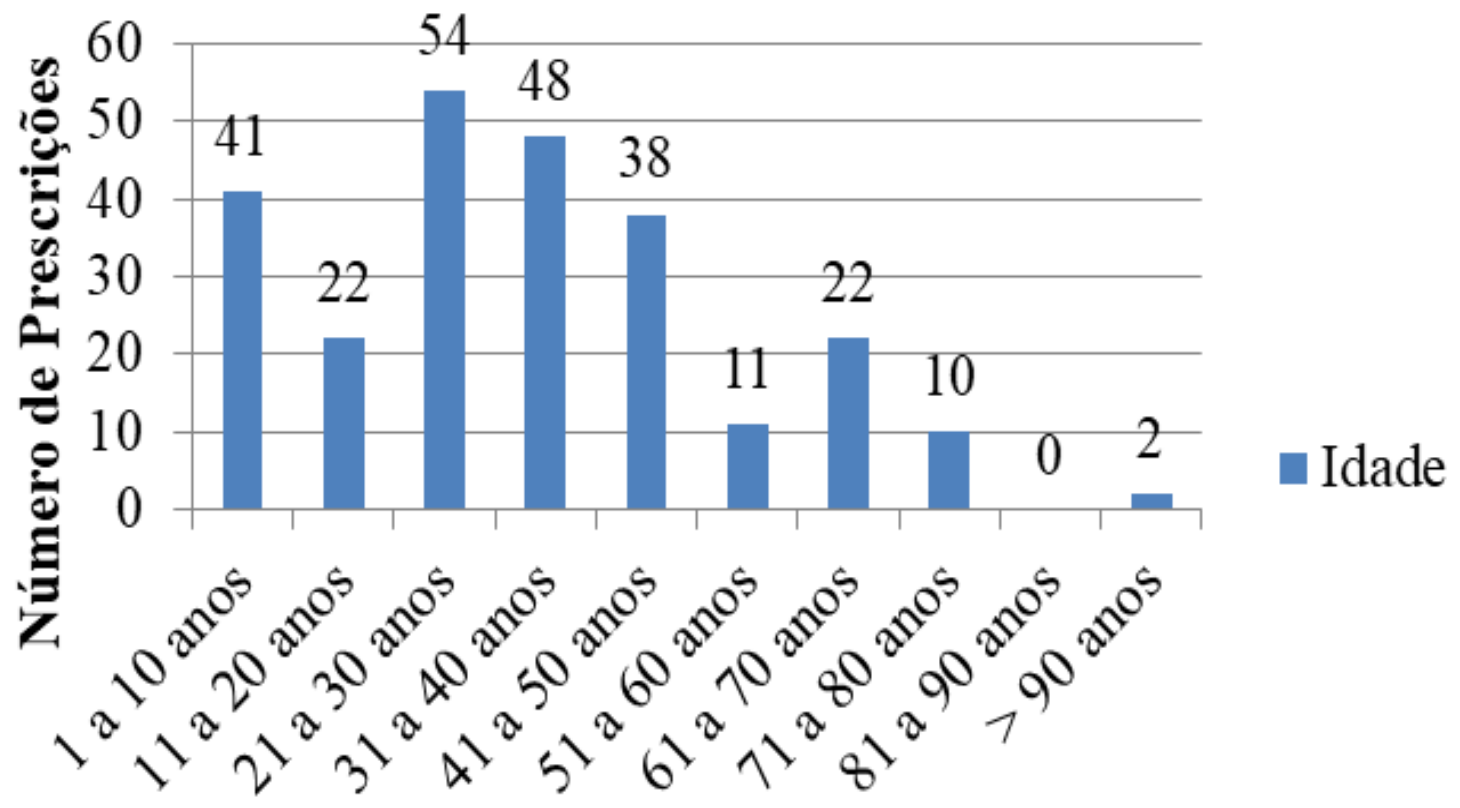

Décadas de Vida

* Fonte: dados da pesquisa (2019).

Ao analisar o Gráfico 2 podemos observar a quantidade de prescrições para utilização de antimicrobianos em relação a cada faixa etária agrupada a cada 10 anos. Optouse por iniciar a graduação da faixa em um ano, pois não houve prescrições relacionadas a infantes com menos de 1 ano de vida.

Assim as faixas etárias de maior concentração foram de 21 a 30 anos, seguido por 31 a 40 anos e 1 a 10 anos, em números absolutos a concentração da dispensação medicamentosa está evidenciada entre 21 a 50 anos, mesma alocação etária percebida em outros estudos relativos a venda de antibióticos (Rojas-Adrianzén, Pereyra-Elías \& Mayta-Tristán, 2016).

Quanto ao encaminhamento do serviço de saúde, categorizou-se a amostra vindas da rede privada ou pública, como pode ser observado no Gráfico 3. 
Research, Society and Development, v. 9, n. 7, e378974278, 2020

(CC BY 4.0) | ISSN 2525-3409 | DOI: http://dx.doi.org/10.33448/rsd-v9i7.4278

Gráfico 3: Venda de antibióticos em 2018, quanto ao setor de encaminhamento em saúde.

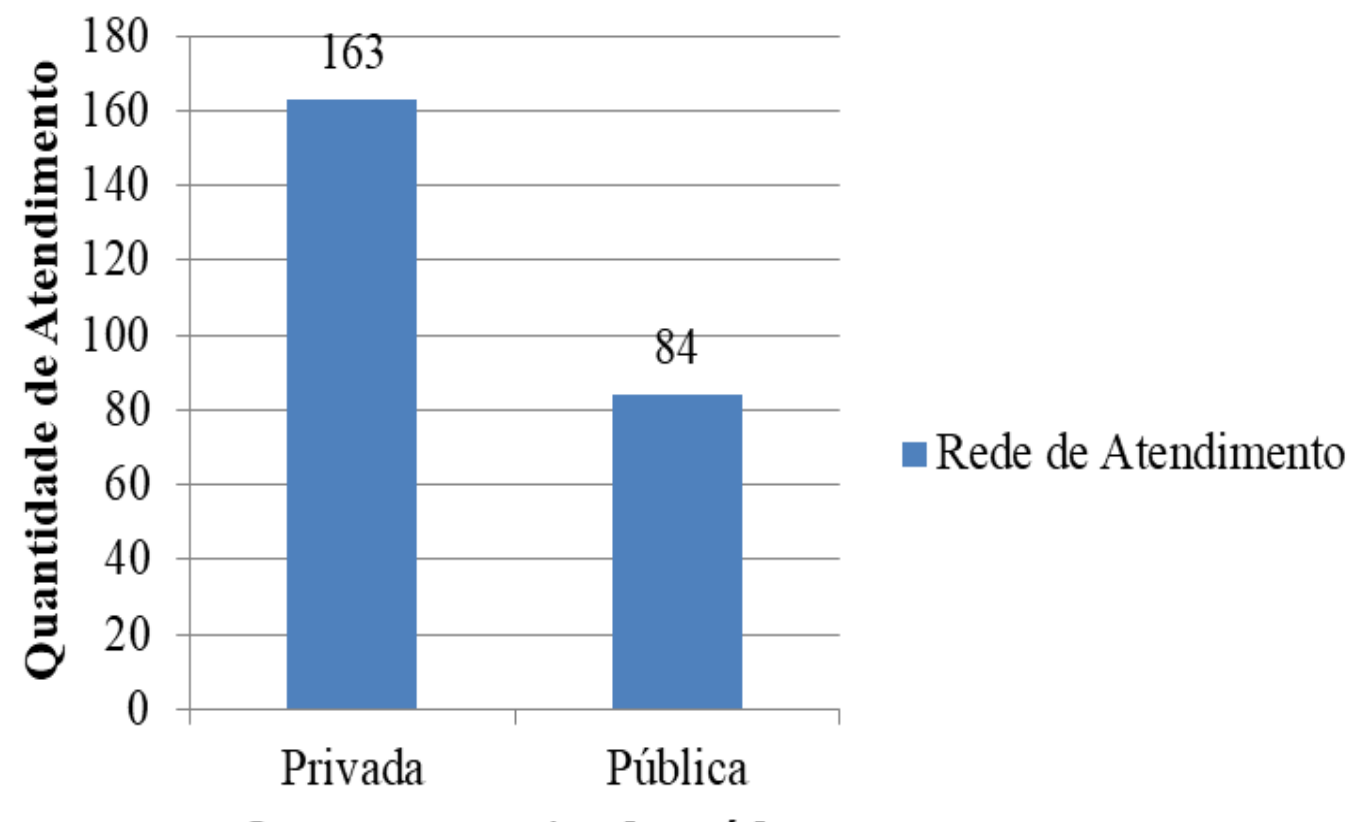

Quanto ao serviço de saúde

* Fonte: dados da pesquisa (2019).

As prescrições trazem informações como dados do paciente, identifica qual foi a clinica ou hospital no qual o este fora assistido, e identifica o tipo de atendimento foi por meio de instituições municipais, estaduais ou federais ligadas ao SUS, ou são da rede particular de saúde.

Contém ainda informações do fármaco, via de administração e posologia, além dos dados do médico que atendeu o paciente. Por isso, este gráfico elucida a origem do encaminhamento do serviço de saúde quanto a venda de antibióticos, vindo da rede pública ou da rede privada de saúde.

Assim foram prescritas 163 receitas de atendimentos vindos da rede privada de saúde e 84 ligadas ao sistema público de saúde. O local onde a farmácia é estabelecida fica de esquina a um Hospital da Rede Privada de Teresina, no bairro existe um posto de saúde da prefeitura de Teresina que presta serviços pelo Sistema Único de Saúde. A proximidade ao hospital privado pode justificar o maior número de vendas de antibióticos para pacientes da rede privada, em detrimento da pública.

Ao todo foram obtidos no banco de dados de SCI para uso de antibióticos 247 vendas, inicialmente categorizamos o número de vendas por meses do ano de 2018, como está demonstrado no Gráfico 4. 
Gráfico 4: Dispersão mensal de antibióticos em 2018 de uma farmácia de bairro em Teresina.

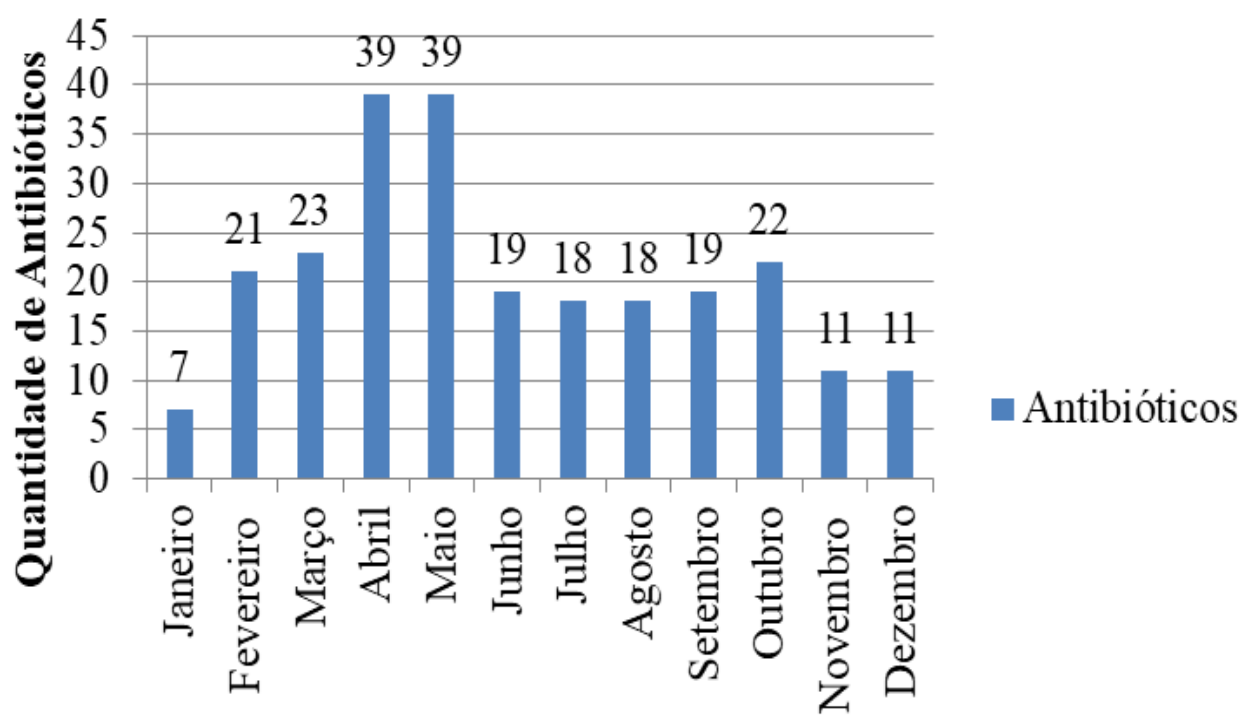

Vendas por meses do ano

* Fonte: dados da pesquisa (2019).

O Gráfico 4 esclarece a distribuição das prescrições médicas de antibióticos ao longo do ano. A pesquisa coletou dados referentes ao ano de 2018, e mês a mês apareceram prescriçoes para o consumo de fármacos com pouca assistência no começo do ano, aumento em dado periodo, seguido de redução, por todo o restante do ano.

Os dados apontam um mês de janeiro tímido 7 prescrições, uma maior concentração na venda de antibióticos relacionados aos meses de fevereiro, março, abril e maio, com dispersão de 21, 23, 39 e 39 unidades respectivamente. Após este período ocorreu uma queda vertiginosa e manteve-se relativamente constante, entre junho e outubro, com nova redução entre o período de novembro e dezembro.

O período do ano em que houve maior número de venda de antibióticos coincide com o período chuvoso da capital Piauiense o que sugere uma correlação entre este fator climático, com a incidência de doenças e o aumento na procura por antibióticos, para combater infecções. É conhecido que fatores climáticos como a chuva, calor e umidade estão associados ao aparecimento de doenças, como observados em estudos publicados na literatura científica, e as doenças respiratórias estão relacionadas ao inverno, em Teresina este “inverno" coincide de fevereiro a maio (Azevedo, Santos, Alves, Azevedo \& Olinda, 2015).

A literatura científica não oferece dados concretos da relação direta entre maior aquisição de antibióticos nas farmácias por indivíduos advindos da rede privada de saúde, mas em termos gerais fica sugerido que a aquisição de medicamentos é bem maior nas farmácias 
(CC BY 4.0) | ISSN 2525-3409 | DOI: http://dx.doi.org/10.33448/rsd-v9i7.4278

privadas como observado em um estudo de Ji-paraná - RO (Fiorotte, Valiatti, Baratela, Alves \& Salvi, 2016). Com relação à venda quantitativa de antibióticos é notória uma retração na quantidade de vendas se compararem com as dispersões anteriores a implantação da legislação vigente (Ladeira, Moraes, Oliveira, Machado \& Barreto, 2017). Essa redução esta diretamente ligada ao cumprimento da Resolução da Diretoria Colegiada RDC n. ${ }^{\circ}$ 44/2010, e contribui para o controle da venda indiscriminada deste tipo de medicamento, assim como atua para controlar a resistência bacteriana (Brasil, 2010).

A pesquisa evidenciou a venda de antibióticos de diversas classes farmacológicas utilizados para inúmeras finalidades e várias vias de administração. Todavia, como este estudo pretende ter noção daqueles mais utilizados, suprimimos a demonstração de todos os fármacos vendidos e evidenciamos os três mais vendidos no período em questão, relacionados Gráfico 5.

Gráfico 5: Antibióticos mais vendidos em uma farmácia comunitária de Teresina, no ano de 2018.

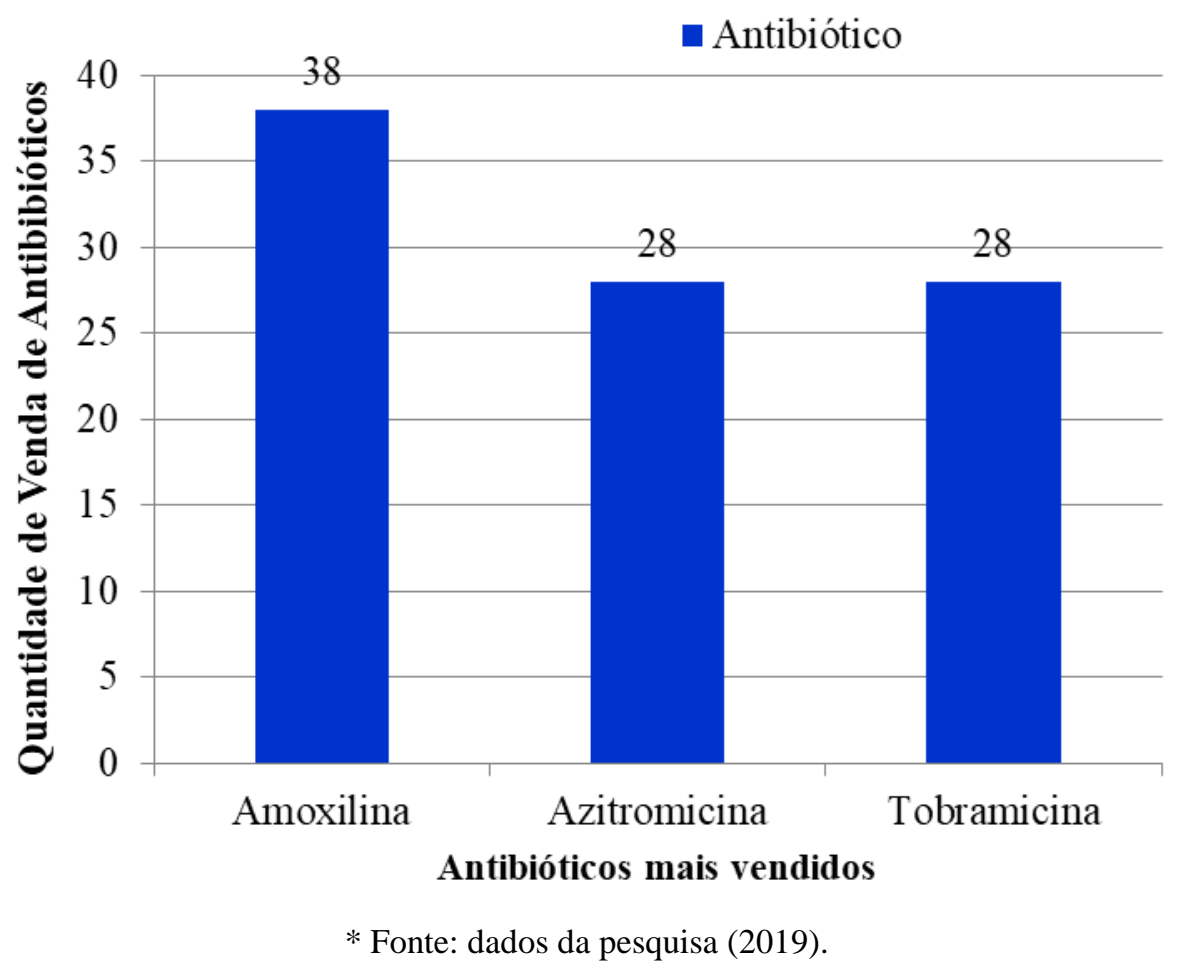

Estes resultados revelam os três antibacterianos mais prescritos vendidos pela farmácia comunitária no ano de 2018. A amoxilina foi a mais indicada, seguido pala azitromicina e tobramicina com a mesma quantidade de indicação terapêutica.

Quanto aos antibióticos mais vendidos pela farmácia, os resultados encontrados vão de encontro com outros estudos publicados (Oliveira, et al., 2016), pois em Teresina a infecção 
mais comum na população diagnosticada na comunidade está condicionada a patologias do trato respiratório. Assim, como afirmam Saço, Leite \& Silvério (2014), o receituário mais presente de amoxicilina vai de encontro a realidade da população, quando relaciona uso de antibiótico e combate a infecções diagnosticadas de pacientes comunitários. Este também foi o antibiótico mais prescrito entre os meses de novembro e dezembro para pacientes na cidade de Imperatriz-MA, um estudo realizado em um município de Muriaé-MG que envolveu 56 farmácias, a amoxicilina foi o antibiótico mais vendido.

\section{Considerações Finais}

O estudo conseguiu alcançar todos os seus objetivos ao mapear a consumo de medicamentos em uma farmácia comunitária em Teresina - PI.

As vendas são em sua maioria proveniente de atendimentos de um hospital da rede privada de saúde, que se encontra ao lado da drogaria alvo deste estudo.

Verificou-se que os antibióticos comercializados pela referida farmácia no ano de 2018, em sua maioria esta ligado a doenças respiratórias, como já era esperado, visto que a capital do Piauí, por conta dos fatores climáticos, as doenças respiratórias são mais comuns, em relação às demais que necessitam do uso de antibacterianos.

Este trabalho pode servir de inspiração para outras pesquisas de estudantes de Farmácia, quanto ao consumo de antibacterianos em Teresina, ou em qualquer outra cidade, ou estado. Uma sugestão em curto prazo é ampliar esta pesquisa ao consultar um número maior de farmácias comunitárias de todas as regiões da cidade, para inferir uma estimativa estatística mais fidedigna a realidade. Em longo prazo recomenda-se um estudo de coorte longitudinal para verificar a evolução nas necessidades de prescrições de antibióticos.

\section{Referências}

Alves LS, Costa LMR, Júnior AR, Nere JM, Costa LF, Garcia LM. ... Santo, LRE. (2014). Perfil da prescrição e dispensação de antimicrobianos em drogaria no município de Montes Claros, MG. EFDeportes.com, Revista Digital. Buenos Aires, 18(190), Mar. Disponível em: https://www.efdeportes.com/efd190/prescricao-de-antimicrobianos-em-drogaria.htm. 
Andrade JV, Vasconcelos P, Campos J \& Camurça T. (2019). Prescrição antibiótica no ambulatório, Acta Med Port, Feb; 32(2):101-110. Disponível em:

https://www.actamedicaportuguesa.com/revista/index.php/amp/article/view/11111/5617.

Arrais PSD, Fernandes MEP, Dal Pizol TS, Ramos LR, Mengue SS. ... Luiza VL. (2016).

Prevalência da automedicação no Brasil e fatores associados. Rev Saúde Pública, 50(supl 2):13s. doi: 10.1590/S1518-8787.2016050006117.

Azevedo JVV, Santos, CAC, Alves TLB, Azevedo PV \& Olinda RA. (2015). Influência do clima na incidência de infecção respiratória aguda em crianças nos municípios de Campina Grande E Monteiro, Paraíba, Brasil. Rev. bras. Meteorol, 30(4):467-477. doi: 10.1590/0102778620140066.

Brandão, Aloísio. (2014). Farmácias: uma abordagem sanitária. Conselho Federal de Farmácia. Disponível em: http://www.cff.org.br/noticia.php?id=1628.

Braoios A, Pereira ACS, Bizerra AA, Policarpo OF, Soares NC. ... Barbosa AS. (2013). Uso de antimicrobianos pela população da cidade de Jataí (GO), Brasil. Ciência \& Saúde Coletiva, 18(10):3055-3060. doi: 10.1590/S1413-81232013001000030

BRASIL. Ministério da Saúde. Agência Nacional de Vigilância Sanitária. (2010). Resolução da Diretoria Colegiada-RDC No 44, de 26 de outubro de 2010. Dispõe sobre o controle de medicamentos à base de substâncias classificadas como antimicrobianos, de uso sob prescrição médica, isoladas ou em associação e dá outras providências. Brasília, DF: Disponível em:

http://bvsms.saude.gov.br/bvs/saudelegis/anvisa/2010/res0044_26_10_2010.html.

Conselho Federal de Farmácia. Orientações farmacêuticas: informativo CFF. Brasília, 2016. Disponível em: http://www.cff.org.br/userfiles/AF_folder_Medicamentos_2016\%20$\% 20$ Impressora.pdf.

Conselho Federal de Farmácia. (2001). Resolução CFF no 357, de 20 de abril de 2001. Aprova o regulamento técnico das Boas Práticas de Farmácia. Brasília: CFF. Disponível em: http://www.cff.org.br/userfiles/file/resolucoes/357.pdf. 
Diaz SJZ. (2015). Proposta de intervenção para reduzir o uso de antibióticos sem prescrição médica na ESF bom sucesso, Arapiraca-AL. Maceió. Monografia [Programa de Pósgraduação em Atenção Básica em Saúde da Família da Universidade Federal de Minas Gerais]. Disponível em: https://www.nescon.medicina.ufmg.br/biblioteca/imagem/sheilajanine-zavala-diaz.pdf.

Fiorotte DT, Valiatti TB, Baratela GNO, Alves FC \& Salvi JO. (2016). A importância da farmácia comunitária na prevenção da automedicação no bairro Colina Park Ji-paraná, Rondônia. Brazilian Journal of Surgery and Clinical Research, 16(1):23-29. Disponível em: https://www.mastereditora.com.br/periodico/20160904_221958.pdf.

Ladeira RC, Moraes WEP, Oliveira CGA, Machado SHM \& Barreto JG. (2017). Perfil de Dispensação de Antimicrobianos antes e depois da promulgação da RDC 44/2010. Acta Biomedica Brasiliensia, 8(2):47-56. Disponível em: https://www.actabiomedica.com.br/index.php/acta/article/download/201/163.

Menezes EA, Oliveira MS, Cunha FA, Pinheiro FG \& Bezerra BP. (2004). Automedicação com antimicrobianos para o tratamento de infecções urinária em estabelecimento farmacêutico de Fortaleza (CE). Infarma, 16(11-12):56-59. Disponível em: http://www.cff.org.br/sistemas/geral/revista/pdf/77/i07-automedicao.pdf.

Oliveira LB, Valle ARMC, Magalhães RLB, Andrade DFR, Sousa AFL. ... Queiroz AAFLN (2016). Prevalência das infecções comunitárias diagnosticadas na estratégia saúde da família. Rev. Bras. Enferm, 10(1):325-332. doi: 10.5205/reuol.7901-80479-1-SP.1001sup201618

Oliveira SB, Barroso SC, Bicalho MA \& Reis AM. (2018). Perfil de medicamentos utilizados por automedicação por idosos atendidos em centro de referência. Einstein (São Paulo), 16(4):1-7. doi: 10.31744/einstein_journal/2018AO4372

Pereira, AS et al. (2018). Metodologia da pesquisa científica. [e-book]. Santa Maria. Ed. UAB/NTE/UFSM. Acesso em: 17 maio 2020. Disponível em: https://repositorio.ufsm.br/bitstream/handle/1/15824/Lic_Computacao_MetodologiaPesquisa-Cientifica.pdf?sequence $=1$. 
Rojas-Adrianzén C, Pereyra-Elías R \& Mayta-Tristán P. (2018). Prevalencia y factores asociados a la compra de antimicrobianos sin receta médica, Perú 2016. Rev Peru Med Exp Salud Publica, 35(3):400-8. doi :https://doi.org/10.17843/rpmesp.2018.353.3458.

Saço LC, Leite ICG \& Silvério MS. (2014). Estudo de comercialização de medicamentos como ferramenta para o uso racional. HU Revista, Juiz de Fora, 40(1 e 2): 97-106. Disponível em: https://periodicos.ufjf.br/index.php/hurevista/article/download/2419/931.

Santos, JR. (2017). Avaliação da procura de antibióticos sem receita médica por clientes de três farmácias no município de Cruz das Almas - BA. Governador Mangabeira. Monografia [Graduação em Farmácia da Faculdade Maria Milza]. Disponível em: http://131.0.244.66:8082/jspui/bitstream/123456789/422/1/TCC\%20FINAL\%20PRONTO\%2 OPRA\%20ENTREGAR.pdf.

São Paulo. (2015). Portaria Secretaria Municipal da Saúde - SMS no 82 de 4 de dezembro de 2015. Normatiza a prescrição e a dispensa de medicamentos no âmbito das Unidades pertencentes ao Sistema Único de Sáude (SUS) sob gestão Municipal. São Paulo, 2015. Disponível em: http://legislacao.prefeitura.sp.gov.br/leis/portaria-secretaria-municipal-dasaude-82-de-5-de-dezembro-de-2015.

Silva FM, Goulart FC \& Lazarini CA. (2014). Caracterização da prática de automedicação e fatores associados entre universitários do curso de Enfermagem. Rev. Eletr. Enf. [Internet], jul/set, 16(3):644-51. Disponível em: https://www.fen.ufg.br/revista/v16/n3/pdf/v16n3a20.pdf.

Veloso DS \& Campelo, V. (2017). Incidência de infecções bacterianas e o perfil antimicrobiano utilizado no tratamento dos pacientes de um hospital de ensino. Rev. Interd. Ciên. Saúde, 4(2):19-28. Disponível em: https://revistas.ufpi.br/index.php/rics/article/download/5053/3908. 
Research, Society and Development, v. 9, n. 7, e378974278, 2020

(CC BY 4.0) | ISSN 2525-3409 | DOI: http://dx.doi.org/10.33448/rsd-v9i7.4278

Porcentagem de contribuição de cada autor no manuscrito

Maria Francisca Ferreira dos Santos - $30 \%$

Valéria Cristina Rodrigues Pereira $-30 \%$

Paulo Renzo Guimarães Júnior - $20 \%$

Manoel Pinheiro Lúcio Neto - $20 \%$ 